REGARDS

SUR L'ECONOMIE ALLEMAND

BULLETIN ECONOMIQUE DU CIRAC
Regards sur l'économie allemande

Bulletin économique du CIRAC

$67 \mid 2004$

Varia

\title{
De l'Etat-Providence à la société de la connaissance
}

René Lasserre

\section{OpenEdition}

Journals

Édition électronique

URL : http://journals.openedition.org/rea/3790

DOI : 10.4000/rea.3790

ISBN : 978-2-8218-0830-0

ISSN : 1965-0787

Éditeur

CIRAC

Édition imprimée

Date de publication : 1 juillet 2004

Pagination : 1-2

ISSN : 1156-8992

Référence électronique

René Lasserre, «De l'Etat-Providence à la société de la connaissance », Regards sur l'économie allemande [En ligne], 67 | juillet 2004, mis en ligne le 08 octobre 2009, consulté le 22 septembre 2020 URL : http://journals.openedition.org/rea/3790 ; DOI : https://doi.org/10.4000/rea.3790 


\section{De l'Etat-Providence à la société de la connaissance}

L'économie allemande a retrouvé le sentier de la croissance et la reprise se consolide, tirée par une conjoncture mondiale favorable et l'excellente tenue des exportations. Cette dernière constitue le signe fort d'une vigueur retrouvée: elle témoigne d'une compétitivité solide des entreprises qui, après de patients efforts de rationalisation, sont parvenues à juguler leurs coûts et font à nouveau la course en tête sur le marché mondial. Cette dynamique externe porte maintenant ses fruits en générant la reprise tant attendue de l'investissement. L'embellie reste cependant en demi-teinte. D'abord parce que les nuages s'amoncellent dans le ciel de l'économie mondiale avec la flambée des prix des matières premières et du pétrole, mais aussi parce que la machine économique interne ne parvient toujours pas à monter en régime.

Le marasme de la demande intérieure semble devoir résister à toutes les thérapeutiques. Ainsi les allègements fiscaux acquis de haute lutte n'auront été qu'un coup d'épée dans l'eau face à la hausse des prix. Voyant leur pouvoir d'achat stagner, confrontés à la persistance du chômage et aux incertitudes qui pèsent sur les régimes de retraite, les ménages hésitent plus que jamais à consommer. L'économie allemande se trouve en quelque sorte enfermée dans une spirale interne de stagnation : les gains de pouvoir d'achat sont absorbés par le poids des prélèvements et des transferts sociaux, tandis que le déséquilibre persistant des budgets publics ne laisse plus aucune marge pour soutenir la demande et relayer la croissance.

Les études que nous consacrons dans ce numéro à l'évolution des comportements de consommation et d'épargne des Allemands, que ce soit à travers l'analyse des changements intervenus dans la structure des budgets des ménages, ou à travers celle de leurs comportements d'achat face à la montée en puissance du hard discount dans le secteur de la distribution, fournissent d'intéressants éclairages sur le manque de ressort de la demande intérieure. Elles tendent justement à montrer que la stagnation de la demande est une tendance lourde, inscrite à la fois dans la démographie, les mécanismes de la protection sociale et les valeurs du corps social et que, par conséquent, elle s'est installée comme un élément durable dans la structure même de l'économie des ménages. Dans un autre registre, celui de la politique menée en faveur des emplois aidés, il apparaît que les différentes mesures mises en œuvre, en dépit de leur ingéniosité, ne parviennent que très partiellement à réinsérer dans l'emploi les inactifs assistés et à élargir ainsi le périmètre de la sphère productive.

Ces données sont autant d'éléments qui nourrissent la réflexion prospective sur les voies possibles d'une réforme du système allemand de régulation économique et sociale. La déficience chronique de la demande domestique met directement en question le coût jugé désormais 
prohibitif de l'Etat-Providence. Elle plaide en faveur de la dérégulation sociale et d'un nouveau partage du revenu qui favorise le travail et l'investissement productif. Convié à nous apporter sa contribution au débat dans le présent numéro, Gabriel Colletis examine attentivement les arguments qui fondent cette alternative libérale, sans toutefois la retenir comme la voie la plus probable. Il estime en effet qu'une dérégulation de grande ampleur mettrait en péril le compromis social sur lequel est fondé l'efficacité du système productif et qu'elle a peu de chances de prévaloir face à la communauté d'intérêts et aux potentiels de compétences qui en assurent le haut degré de performance. C'est plutôt dans la valorisation de ces potentiels de compétences et de savoirs que l'Allemagne dispose des meilleurs atouts et qu'elle est en mesure de s'assurer les avantages compétitifs durables d'une accession progressive à l'économie de la connaissance.

René Lasserre $30 / 06 / 2004$ 